\title{
O aborto em pauta: uma análise sobre o tema no Uruguai entre 1934 e 2012
}

\section{Dércio Fernando Moraes Ferrari ${ }^{1}$}

Resumo: O objetivo do texto é analisar a questão do aborto no Uruguai entre meados do século XX e início do século XXI, como consequência de reivindicações das mulheres uruguaias perante manifestações. O país que tivera o aborto descriminalizado entre 1934 e 1938, voltou a legislar em 2012, como resultado de reivindicações de movimentos sociais e o apoio da Frente Ampla (FA). Analisar os fatores que levaram a aprovação em 1934 e em 2012, também se estabelece como um objeto de estudo, indo na "contramão da América Latina", como têm denominado a mídia. Com a aprovação dessa política pública o Uruguai acaba ainda por retomar um tema tão esquecido no continente, onde muitas vezes a questão acaba sendo vinculada a ideologias filosóficas e religiosas, e não como uma questão de saúde pública.

Palavras-chave: Uruguai; Descriminalização do aborto; Reivindicações; Políticas públicas.

\section{ABORTION IN AGENDA: AN ANALYSIS OF THE SUBJECT IN URUGUAY BETWEEN 1934 AND 2012}

\begin{abstract}
The objective of this study is analyze the issue of the abortion in Uruguay's between mid of the twentieth century and beginning of the twenty-first century, from the perspective of claim of the Uruguayan woman's. The country that had the abortion decriminalized between 1934 and 1938, return to legislate about the theme in 2012, as result of claims of social movements and the support of the Board Front (BA). Analyze the factors that take the adoption in 1934 and 2012, also arises like an object of study, going on the "against of the Latin America", as the media has called. With the approve of this public policy, Uruguay's rescues a theme so forgotten in the continent, so many times the question is assigned to the religious and philosophies ideologies, not like a question of public health.
\end{abstract}

Keywords: Uruguay; Decriminalization of the abortion; Claims; Public policies.

\footnotetext{
${ }^{1}$ Mestrando do Programa de Ciências Sociais da Unioeste Toledo/Paraná.
} 


\section{INTRODUÇÃO}

Algumas ações realizadas por José Mujica têm feito com que a mídia denomine o caminho legislativo percorrido pelo Uruguai como a contramão da América Latina. Leis como a regulamentação da Cannabis psicoativo, do casamento homoafetivo e da descriminalização do aborto têm sido aprovadas no país durante os governos frenteamplistas, ganhando foco a questão social durante a gestão de Pepe Mujica.

Ao olhar a questão do aborto sob uma perspectiva de saúde pública e não mais criminal, a criação da Lei $\mathrm{n}^{\circ} 18.987$ de 22 de outubro de 2012 prevê a descriminalização do aborto desde que o procedimento seja realizado nas medidas propostas pela lei e até a $12^{\mathrm{a}}$ semana de gestação. Porém, a discussão do aborto no Uruguai é antiga, onde a primeira normativa sob o tema surgiu ainda em 1934, alterando o Código Penal de 1898 e despenalizando além do aborto a eutanásia no país.

Para a compreensão de tais leis deve-se levar em conta a conjuntura política do país nos dados contextos históricos. No contexto da reforma no Código Penal em 1934, o país encontrava-se movido pelo batllismo, que "pretendia a normalização das instituições políticas, econômicas, sociais e culturais do país" e assim acabaria por levar o Uruguai a ser o primeiro país a implantar o Estado do bem-estar social na América Latina e representar naquele momento algumas implantações de medidas reivindicadas pelo movimento feminista no Uruguai, como a despenalização do aborto e a iniciativa do divórcio por parte da mulher (SOUZA, 1998, p. 181). O objetivo deste trabalho é analisar as reivindicações das uruguaias nos dois momentos, bem como as implicações sociais de tais medidas, onde espera-se analisar a efetiva participação desses grupos em cada um dos momentos histórico delimitados. Uma análise quantitativa do aborto não é a proposta desse trabalho.

De acordo com Mohanty (2008, p. 79), uma política liberal como é o caso da regulamentação da Cannabis psicoativo e da descriminalização do aborto merece uma atenção especial do meio acadêmico, principalmente por tratar-se de um país que passou por um processo de colonização, como foi o caso do Uruguai e da América Latina de um modo geral. Outro ponto importante para se pensar tais questões é ainda levar em conta que ambas as situações surgem por meio de reivindicações de atores sociais, seja por meio de instituições políticas do Estado ou movimentos sociais e ONG's. 
Analisar o contexto da sociedade uruguaia e latino-americana de um modo geral dentro de um processo colonizador, nitidamente machista e dominador contribui para entender a luta pelo aborto e pela liberdade do corpo feminino dentro do Estado. O neocolonialismo e suas entranhas instauradas a partir dos anos 1980 deixaram ainda mais grave e delicada a situação de dominação e as relações de poder no subcontinente, dificultando assim a discussão de temas como aborto, casamento homoafetivo e regulamentação da maconha.

\section{O QUE HÁ ENTRE O URUGUAI DE 1934 E 2012?}

A questão do aborto em um país majoritariamente cristão, como é o caso do Uruguai merece um destaque especial do meio acadêmico, onde questões centrais devem ser levadas em conta para a compreensão deste debate: Quais motivações de um pequeno país latino americano e tradicionalmente católico a legislar a respeito do aborto? Ou melhor: O que faz com que essa questão seja reivindicada politicamente a mais de 30 anos?

Antes de entrar especialmente no caso uruguaio deve-se analisar a questão do aborto junto ao movimento feminista. Tal reivindicação torna-se pauta quando as mulheres avançam para um segundo patamar de discussão, onde questões como o voto, equiparação salarial, ou ainda o próprio reconhecimento já haviam sido parcialmente atingidas, ainda que em alguns casos muito superficialmente no plano jurídico. A questão do aborto muitas vezes é vista pela sociedade como um atentado à vida, ou seja, prevalecendo assim o discurso religioso sobre o social, do ponto de vista do Estado. Em contrapartida, as mulheres que reivindicam tal medida analisam a questão justamente pelo oposto, onde a questão é vista como uma ideia de liberdade do próprio corpo, envolvendo questões como sexualidade, reprodução, amor e controle reprodutivo.

$\mathrm{Na}$ maioria das vezes é atribuída ao grupo que reivindica tal medida uma associação entre o público e o privado, o individual e o coletivo ou ainda entre o laico e o confessional, jogando a questão para uma opção religiosa ou ética pessoal da mulher. Esse conflito, que no país teve início em princípios do século XX, acabou por levantar profundas questões na sociedade uruguaia. O tema constituiu-se ainda como centro de debates e argumentações que articulam distintos discursos sobre a vida privada e as relações íntimas, principalmente quando o mesmo passou de um patamar 
reivindicativo e entrou para o campo legislativo. Nesse momento, a temática acaba sendo então objeto de discussão de governantes, parlamentaristas e juristas, ganhando assim a sexualidade e a liberdade do corpo o interesse do Estado no campo jurídico (SAPRIZA, 2011, p. 22).

$\mathrm{Na}$ análise da questão do aborto no caso uruguaio, ainda devem ser levantadas questões mais profundas tocantes ao tema que a própria realidade do país, como a função reprodutora, que foi construída em torno da mulher por parte da sociedade e da Igreja ao longo do século XVII e foi intensificada pelo movimento iluminista. A busca por métodos abortivos clandestinos muitas vezes é motivada por um sentimento que teme o julgamento por parte de uma sociedade tradicionalmente sexista, onde questões éticas são levantadas como argumento contrário a esse grupo de mulheres que foram historicamente marginalizadas e ainda enfrentavam - e enfrentam - problemas congênitos de uma sociedade que herdou toda a estrutura heterosexista e hierarquizada imposta pela metrópole durante o processo de colonização.

Para uma melhor compreensão do tema devem ainda ser levados em conta os discursos, que no caso uruguaio são desenvolvidos a partir de quatro grupos: feministas, que reivindicam a despenalização do aborto, médicos ginecologistas e de outras áreas, a Igreja Católica e os representantes do Estado. Esses mesmos grupos encontravam-se divididos em 1934 e ainda encontramse em 2014, porém com a aprovação da Lei n ${ }^{\circ} 18.987$ ocorreu a entrada de outro grupo que no contexto do início do século XX não tinha tanto espaço em tal discussão: as mulheres contra a descriminalização do aborto. Esse grupo encontrou em 2012 apoio principalmente nos partidos Blanco e Colorado, devido a oposição parlamentar desenvolvida pelos dois grupos dentro do Senado.

No contexto de 1934 devem ser levadas em conta as consequências do batllismo no Uruguai, que afetaram profundamente a sociedade uruguaia, principalmente no campo social, com a ampliação e abrangência da Constituição da época e leis que previam uma maior cobertura da população. Nesse sentido a mudança do Código Civil de 1898 no ano de 1934 foi o primeiro passo para tais mudanças.

Tal reformulação fícou a cargo de José Irureta Goyena, um renomado jurista liberal e antibatllista, que encontrou na ditadura conservadora instaurada por Gabriel Terra uma brecha que acabara por surpreender naquele momento boa parte da população uruguaia, devido a modificação do Código Penal despenalizando a questão do aborto e permitindo a prática da eutanásia, denominada na época de homicídio por piedade e aplicada em casos de extremo sofrimento de um paciente em que os 
recursos médicos da época não permitiam reversão do quadro de saúde do paciente (BARRÁN, 1995, p. 110).

Naquele momento a questão do aborto não fora normatizada amplamente como ocorrera em 2012, porém ocorreu sua despenalização no Código Penal. Durante os quatro anos de vigência da despenalização (1934-1938) a questão passou por intensa contestação por parte de políticos conservadores ligados à Igreja e setores que opunham-se a despenalização do aborto. Nesse período, diferentemente do que ocorre a partir de 2012 a mulher não tinha no Estado o aparato clínico para a realização da prática abortiva, o que por sua vez embasava o argumento da oposição de Goyena, que via na despenalização do aborto, além da problemática religiosa um perigo para as mulheres recorrentes a tal prática, onde nenhuma medida de segurança seria tomada e o Estado naquele momento pouco oferecia em questões de conscientização e suporte, caso a mulher optasse pela prática.

Ao pensar na questão do aborto e sua despenalização enquanto redigia o Código Penal, Goyena encontrou duas problemáticas no tocante as representações morais e filosóficas no qual a mulher era vista após a prática abortiva, uma que a considerava uma prostituta e outra em que o seu parceiro, caso tivesse a apoiado não seria mais visto como um "homem de honra" (SAPRIZA, 2011, p. 36).

Para compreender as reivindicações das mulheres "pró-aborto" em 1934 deve-se levar em conta ainda que o grupo que lutava por tal direito naquele momento tinha objetivo muito distinto do grupo que lutou nas duas últimas décadas pela questão do aborto. Em 1934 o Uruguai vivia um momento de transição demográfica e assim como boa parte das nações latino americanas estava entrando em um processo de urbanização acelerado e teria como consequência uma redução na alta taxa de natalidade da época.

Porém, diferentemente de algumas nações vizinhas, o país recebeu uma maior influência da teoria neomalthusiana, onde os médicos acabaram por ser os intermediadores entre as minorias e o Estado, criando um discurso que acabara por substituir o discurso religioso no tocante a "inferioridade da mulher", tanto debatida pela Igreja anteriormente.

Nota-se no discurso médico da época, especialmente de ginecologistas, argumentos em que colocavam as mulheres como "perigosas para a saúde do homem", o que agravava ainda mais a ideia de submissão tanto debatida pelo feminismo uruguaio e mundial naquele momento. 
Em contrapartida das reivindicações das mulheres da época, o Estado que apoiara o aborto naquele breve período tinha outro objetivo: reduzir a natalidade, visto que o objetivo do Estado, tal como questionou o obstetra Augusto Turenne em 1926 em uma conferência do S.M.U. (Sindicato Médico del Uruguay) onde em sua fala propôs a problemática aos uruguaios ali presentes: "Queremos ser mais ou queremos ser melhores?", indagando sobre um possível aumento populacional ou uma melhoria na qualidade de vida. Embora Turenne não fosse favorável ao aborto, seu discurso foi interpretado positivamente pelos que levantavam a bandeira do aborto enquanto controle de natalidade, ou seja, o Estado (TURENNE, 1926, p. 1).

Naquele momento a discussão ainda era intensa devido ao embate acerca da proteção do direito à vida. Enquanto Goyena trabalhava com a ideia de que a vida a ser preservada e protegida era a da mãe, visto que na visão do jurista - sob o aspecto cientifico - o embrião era apenas um componente provisório do corpo materno. Já a oposição, pautada no discurso religioso que defendia o criacionismo e a predestinação do embrião como argumento contrário, onde os argumentos discorriam-se em torno da defesa do coletivo (mãe e embrião).

Embora todo o debate em torno do tema, naquele momento o aborto foi despenalizado apenas em situações em que a gravidez apresentasse risco de vida à mãe, impedindo inclusive que parteiras tradicionais no contexto da época - realizassem qualquer procedimento de interrupção da gravidez, cabendo tais procedimentos a área médica. A despenalização do aborto voluntário ocorreria apenas em meados de 1935, quando ao mesmo tempo a impressa começou a difundir negativamente tal medida, sendo responsável pela formação de opinião.

A grande pressão da mídia, juntamente com o conservadorismo parlamentar e a Igreja, levaram o parlamento a reunir-se durante três vezes entre 1936 e 1937 para debater a respeito do tema, o que ocasionou a penalização novamente do aborto, resultado de uma nova alteração no Código Penal uruguaio em 1938 que duraria até 2012.

Em 2012, como resultado de profundas transformações sociais e no modo de vida uruguaio, como a conquista do mercado de trabalho por parte da mulher e a ação de movimentos sociais e ONG's, o país voltou novamente a legislar sobre o tema, agora numa perspectiva mais profunda, onde por meio da Lei $\mathrm{n}^{\circ} 18.987$ o aborto passou a ser não só descriminalizado mas também normatizado. 
Antes de realizar uma análise da referente lei é necessário compreender o contexto que a mesma surge, onde indagações como "Quais eram as reivindicações neste momento?” e "Quais foram as mudanças efetivas, se comparada a lei do início do século XX?" tentarão ser compreendidas.

No contexto da aprovação da nova lei na segunda década do século XXI, questões como a conquista do mercado de trabalho por parte das mulheres e sua posição nele não fazem-se mais tão necessárias quanto em outros contextos históricos, como caracterizavam-se de fins dos anos 1930 a meados dos anos 1980. Nesse momento e na atual realidade uruguaia é necessária uma luta por identidade regional e pelo rompimento com os vestígios do capitalismo colonial e a herança custosa deixada pela metrópole pós-independência, que acaba por atingir principalmente grupos minoritários da sociedade.

Ao tratar da colonialidade do poder, como consequência de uma herança colonial, Aníbal Quijano conclui que essa dominação a respeito da ideia de colonizado, é resultado de "uma construção mental que expressa a experiência básica da dominação colonial e que desde então permeia as dimensões mais importantes do poder mundial, incluindo a racionalidade específica, e eurocentrismo". O autor propõe que a herança colonial tenha sido mais duradoura e hegemônica que outras influências hoje mundialmente disseminadas (QUIJANO, 2014, p. 777). Ainda segundo o autor, tal disparidade é consequência de uma relação entre colonizador e colonizado, que a longo prazo acabaram por interferir diretamente em questões contemporâneas complexas, como a resistência em legislar sobre temas liberais, como a questão do aborto.

\section{A LUTA PELA DESCRIMINALIZAÇÃO E A OPOSIÇÃO CONSERVADORA}

Ao tratar do aborto no contexto social atual, em primeiro lugar é importante salientar que a Lei $\mathrm{n}^{\circ} 18.987$ surge como resultado de um debate em torno do aborto com mais de 30 anos, onde ONG's como a MYSU - Mujer y Salud en Uruguay e Cotidiano Mujer vem trabalhando com campanhas "próaborto", apresentando dados e estatísticas a respeito do aborto no país ao longo dos últimos anos e lutando pelo poder da mulher sobre seu próprio corpo perante o Estado.

Essa luta pelo aborto representa ainda uma autonomia da mulher em relação ao próprio corpo, onde a liberdade de decidir a continuidade ou não da gestação representa tal autonomia e poder. Em um 
de seus estudos, Michel Foucault apresenta um dos papéis que a sociedade pode apresentar no que se refere ao conceito poder, onde segundo o autor as instituições acabam por ser mecanismos disciplinares e:

[...] a análise em termos de poder não deve postular, como dados iniciais, a soberania do Estado, a forma da lei ou a unidade global da dominação; estas são apenas e, antes de mais nada, suas formas terminais. Parece-me que se deve compreender o poder, primeiro, como a multiplicidade de correlações de força imanentes ao domínio onde se exercem e constitutivas de sua organização; o jogo que, através de lutas e afrontamentos incessantes as transforma, reforça, inverte; os apoios que tais correlações de força encontram umas nas outras, formando cadeias ou sistemas ou, ao contrário, as defasagens e contradições que as isolam entre si (FOCAULT, 1988, p. 88-89).

As contribuições de Foucault permitem uma análise a respeito da questão do aborto, pois a compressão da questão da "criminalização moral do indivíduo", onde mesmo com a ausência da criminalização jurídica, a mulher que opta (mesmo com a lei vigente) pela realização do aborto acaba por ser julgada, seja em seus princípios filosóficos ou atitudes. De acordo com o autor isso ocorre pois as instituições, como família, igreja e escola, imprimem esse poder na mulher com a finalidade de opressão.

Esse poder dado as instituições nos países da América Latina é mais intenso pelo fato da origem destes países ter sido por meio de uma colonização de exploração, onde tal modelo socioeconômico acabou por trazer as nações independentes um poder interligado aos aparatos estatais e nas instituições.

Como consequência de tais reivindicações, em 2008 o Senado chegou a legislar sobre o tema, porém sem a maioria e o apoio presidencial a questão foi vetada e voltou a ser pautada durante o governo de José Mujica em 2012.

Já em segundo lugar, é importante ressaltar ainda que a recente lei também possui oposição por parte de grupos conservadores, que liderados pelos partidos tradicionais e opositores à Frente Ampla de José Mujica, chegaram a convocar em 2014 um referendo para a realização de um possível plebiscito para a continuidade ou não da lei. 
Tal referendo contou com a participação de 232.841 uruguaios, totalizando 8,8\% de votos contra a lei, que de acordo com a constituinte do país os números não foram suficientes para a convocação de um plebiscito, onde tais números deveriam ter atingido no mínimo os $25 \%$ necessários para uma nova instância de consulta, mantendo assim a Lei de Interrupção Voluntária da Gravidez vigente (DOMÍNGUEZ, 2014, p. 1).

No que refere-se aos objetivos, a Lei $\mathrm{n}^{\circ} 18.987$, tem como objetivo reduzir o número de mortes por práticas clandestinas de aborto e normatizar por parte do Estado todo o processo de realização do mesmo, onde não caracteriza-se como objetivo do governo o controle de natalidade, diferente do que ocorrera em 1934. A referida lei prevê ainda, em seu art. $6^{\circ}$ que:

o Estado garantirá o direito de reprodução consciente e responsável, reconhecendo o valor social da maternidade, a tutela a vida humana e promove o exercício pleno dos direitos sexuais e reprodutivos de toda a população, de acordo com o previsto no Capítulo I da Lei $\mathrm{N}^{\mathrm{o}} 18.426$, de $1^{\circ}$ de dezembro de 2008. A interrupção voluntária da gravidez, que se prevê na presente lei, não constitui um instrumento de controle de natalidade (URUGUAI, Presidência da República Oriental do Uruguai. Lei no 19.172, de 20 de outubro de 2012, p. 06).

Ao assumir as reivindicações das mulheres por meio de tal política pública o Estado passa a tratar do tema como uma questão de saúde pública, onde todo o aparato estruturado em torno da normativa prevê a saúde da mãe, evitando futuras complicações de abortos clandestinos. A descriminalização do aborto por meio da Lei $\mathrm{n}^{\circ} 18.987$ vem para revisitar o Capítulo IV, artigos 325 e $325 b$ do Código Penal Uruguaio, uma vez que antes da aprovação da lei o mesmo previa que "a mulher que causar seu aborto ou consenti-lo será punida com prisão de três a nove meses", bem como um terceiro participante que a tenha auxiliado, seja com participação primária ou secundária será punido de seis a vinte quatro meses de prisão (RETA, A.; GREZZI, O.; SALOM, C., 2011, p. 578).

Porém é importante ressaltar que políticas públicas desse tipo, voltadas para minorias começaram a ganhar espaço nas agendas governamentais apenas no fim dos anos 1990 e início do século XXI. Tal ampliação das agendas e debates governamentais mais amplos ocorreram após a chegada da esquerda e da centro-esquerda ao poder. Nesse momento ocorreu uma reorganização da agenda pública na maioria dos países sul-americanos, como foi o caso da Venezuela com Hugo Chávez 
(1999), do Brasil com Lula (2002), da Argentina com Néstor Kirchner (2003), do próprio Uruguai com a eleição de Tabaré Vázquez (2005), marcando o primeiro governo frenteamplista no país, da Bolívia com Evo Morales (2006) e do Chile com Michelle Bachelet (2006). Vale ressaltar ainda, que mesmo com o fim do neoliberalismo várias nações apresentam resistência em legislar sobre o tema e o incluir em suas agendas de governo (AYERBE, 2008, p. 265).

Ainda no que refere-se a lei de interrupção voluntária da gestação, ficam estabelecidos como requisitos para a interrupção gestacional, em seu artigo $3^{\circ}$, que dentro das 12 semanas de gestação, a mulher que desejar realizar tal procedimento deve procurar o SNIS (Sistema Nacional Integrado de Salud), onde passará por uma consulta prévia, onde deve demonstrar o interesse na realização da prática bem como suas motivações.

Realizado o primeiro contato com a equipe médica, a gestante é encaminhada para uma nova consulta onde passará por uma equipe de três quadros profissionais, sendo composta por no mínimo um médico ginecologista, um psicólogo e um assistente social. Tal equipe tem ainda por finalidade dar a mulher informações sobre as principais características da lei, bem como as implicações de um abordo e expor ainda as alternativas ao aborto, como programas de apoio socioeconômico e a possibilidade de dar a criança para adoção, caso decida por dar continuidade a gestação.

Após tal consulta é dado a mulher um prazo de reflexão, sendo de no mínimo cinco dias, onde a equipe interdisciplinar deverá deixar registrado no histórico clínico da paciente sua decisão, seja ela realizar a prática legal do aborto ou ainda continuar com a gestação. Tal equipe será o intermédio entre a mulher e o Estado, onde por meio de uma formação contínua tais profissionais estarão capacitados para todo o processo de informação à mulher, bem como do processo de interrupção gestacional, que tem implicações físicas, psicológicas e sociais.

A análise da lei referente a interrupção voluntária da gravidez permite observar sua abrangência e aplicabilidade, visto que o objetivo da mesma é tratar o aborto não mais como crime, pois trata-se então de uma questão de saúde pública, não podendo mais ser apenas tratada como um problema criminal, visto que os índices de abortos clandestinos são preocupantes no país, embora ainda seja um dos mais baixos do continente. Estudos realizados por Sanseviero et al. em 2002, concluem que a média de abortos naquele ano era de cerca de 33.000. Para a obtenção dos dados os autores levaram em conta três tipos de dados: os relatórios dos nascidos vivos, altas hospitalares por questões 
que envolvam a interrupção da gravidez e dados de clínicas clandestinas para a realização da prática (SANSEVIERO, R., et al., 2011, p. 174).

Com o aborto criminalizado como era no período levantado pelos autores, até coleta de dados é complexa, pois muitas vezes não representa a realidade pelo fato de que as mulheres que realizavam tal prática clandestinamente a realizavam geralmente em casa, não entrando assim nas estatísticas oficiais do Ministério da Saúde.

Pensar a questão do aborto em um mundo globalizado e capitalista, onde cada vez mais a ideia de local por uma corrente antropológica tem desaparecido, sendo necessário ir além da simples associação de local com o regional, onde os novos debates "sobre a economia e o lugar parecem ser especialmente úteis neste aspecto [...], o lugar afirma-se em oposição ao domínio do espaço, e o nãocapitalismo em oposição ao domínio do capitalismo como imaginário da vida social” (ESCOBAR, 2005, p. 145).

É com base nos estudos de Escobar e de outros antropólogos que alguns movimentos sociais e ONG's têm lutado pela questão do aborto, não somente no caso uruguaio. A necessidade de superação da influência capitalista e eurocentrista hoje é chave para avançar em questões como o aborto, onde nota-se na América Latina uma ausência de debates legislativos em torno do tema.

Muitos governantes acabam por deixar o tema omisso ao invés de propor medidas eficazes para a solução desse problema de saúde pública que assola o subcontinente. Tal omissão muitas vezes ocorre pelas representações sociais que são construídas a um governante ou candidato à presidência ao tratar do tema. No contexto sul-americano atual, ao declarar-se favorável ao aborto, legalização da maconha ou casamento homoafetivo, por exemplo, ainda são motivos de uma associação entre o público e o privado, levando assim alguns setores mais conservadores da sociedade a gerar oposição aos governantes ou candidatos.

\section{CONSIDERAÇÕES FINAIS}

O contexto social em que o aborto foi legislado no Uruguai entre 1934 e 2012 sofreu profundas mudanças. O país acabara por entrar em um campo mais diversificado da economia, rompendo com a economia pautada exclusivamente na agropecuária e impulsionando uma maior 
integração regional. Nesse meio tempo a questão do aborto encontrou-se fora de pauta nos programas governamentais do país, sendo destaque novamente em 2012.

Enquanto em 1934 a luta pelo aborto era principalmente realizada por um representante do Estado e por um grupo de mulheres que objetivava o controle reprodutivo, e tal luta acabou por resultar em uma reforma no Código Penal. Em 2012 a situação é mais ampla de ser analisada. A Lei n ${ }^{\circ} 18.987$ além de despenalização do aborto, alterando novamente o Código Penal Uruguaio amplia a participação do Estado enquanto aparato de garantia da saúde da mulher.

Nesse segundo momento, além da função mais ampla do Estado nota-se uma maior participação de ONG's que acabaram por motivar a reivindicação que gerou a normativa. O papel dessas ONG's e demais movimentos sociais na panfletagem e conscientização sobre o tema, deu as uruguaias novamente o poder sobre o seu próprio corpo, uma vez que decidir a respeito de uma gestação é a confirmação dessa autonomia.

Por fim, um ponto importante que deve ser levado em conta ainda é de que a questão do aborto não está solucionada no país, visto que os opositores da lei, juntamente com grupos religiosos demonstram publicamente sua insatisfação com a recente lei.

\section{REFERÊNCIAS}

AYERBE, Luis Fernando. Novos atores políticos e alternativas de governo na América do Sul: os casos de Argentina, Bolívia, Brasil e Venezuela (p. 265-301). In: AYERBE, L. F. (Org.). Novas lideranças políticas e alternativas de governo na América do Sul. São Paulo: Ed. UNESP, 2008.

BARRÁN, José Pedro. Historia de la sensibilidad en el Uruguay: La cultura Barbara. (1800-1860). Tomo 1. Montevideo: Ed. La Banda Oriental, 1995.

DOMÍNGUEZ, María Noel (ed.). No habrá referéndum sobre aborto: el club de los ocho. Disponível em: <http://www.montevideo.com.uy/auc.aspx?204262,245,0,0>. Acesso em: 30 out. 2014. 
ESCOBAR, Arturo. O lugar da natureza e a natureza do lugar: globalização ou pós-desenvolvimento?. In: LANDER, Edgardo (org). A colonialidade do saber: eurocentrismo e ciências sociais. Buenos Aires: CLACSO - Colección Sur Sur, 2005, pp.133-168.

FOUCAULT, Michel. História da Sexualidade I: a vontade de saber. 9ed. Rio de Janeiro: Graal, 1988.

MOHANTY, Chandra. Bajo los ojos de Occidente, revisitado: la solidaridad feminista através de las luchas anticapitalistas. In: NAVAZ, Suárez, L.; HERNÁNDEZ, R. A. (Orgs.). Descolonizar el feminismo: teorías y prácticas desde los márgenes. Madrid: Cátedra, 2008.

QUIJANO, Aníbal. Cuestiones y horizontes: de la dependencia histórico-estructural a la colonialidad/descolonialidad del poder. Buenos Aires: CLACSO, 2014.

RetA, A.; GREZZI, O.; SALOM, C. Código Penal de la República Oriental del Uruguay. 8 ed. Montevideo: Fundación de Cultura Universitaria, 2011.

SANSEVIERO, R.; ROSTAGNOL, S.; GUCHÍN, M.; MIGLIÓNICO, A. Condena, tolerancia y negación: el aborto en Uruguay. Montevideo: Universidad para la Paz, Naciones Unidas, 2003.

SAPRIZA, Graciela. Historia de la (des)penalización del aborto en Uruguay. "Aborto libre": la corta experiencia uruguaya (1934-1938). In: JOHNSON, Niki. et al. (Des)Penalización del aborto en Uruguay - prácticas, actores y discursos: abordaje interdisciplinario sobre una realidad compleja. Montevideo: CSIC, 2011.

SOUZA, Marcos Alves. O reformismo uruguaio sob a égide do "batllismo" na primeira metade do século XX. In: ENCONTRO DA ANPHLAC, 3., 1998, São Paulo. Anais Eletrônicos do III Encontro da ANPHLAC. São Paulo: ANPHLAC, 1998. 
TURENNE, A. El aborto criminal es um grave problema nacional. Montevideo: S.M.U., conferencias dictadas em el Sindicato Médico del Uruguay, 1926.

URUGUAI. Presidência da República Oriental do Uruguai. Lei nº 19.172, de 20 de outubro de 2012. Interrupción Voluntaria del Embarazo. Montevideo: Ministerio de Salud Pública, 2012. 